\title{
The Effect of Turbulence Models on Coolant Temperature and Velocity for the Pebble-Bed Typed High Temperature Reactor
}

\section{Muhammad Subekti}

Center for Nuclear Reactor Technology and Safety, (BATAN) Puspiptek area building No. 80 Serpong,Tangerang Selatan 15310, INDONESIA

\section{Abstract}

The 3D thermal-hydraulics analysis based on Computational Fluid Dynamics (CFD) has a role to analysis more detail the reactor safety, especially for pebble-bed typed High Temperature Reactor (HTR). A realistic pebble arrangement becomes a challenge to be modeled based on the Simple Cubic (SC), Body-Centered Cubic (BCC) and Face-Centered Cubic (FCC). Furthermore, CFD calculation could utilizes laminar model as well as turbulence model such as $k-\epsilon, k-\omega$ and Reynold stress model (RSM). Therefore, the objective of this reseach is to analyze the effect of turbulence model on temperature and coolant velocity distribution using FCC on pebble-bed typed HTR as well as investigation of the turbulence models. The comparison shows that all models are acceptable for HTR-10 case with the difference by the range of $0.03-0.33 \%$ for the temperature parameters, in which the minimum different is obtained by $k-\epsilon$ model.

Muhammad Subekti,

email: subekti@batan.go.id

Received: 29 July 2016

Accepted: 21 August 2016

Published: 21 September 2016

\section{Publishing services} provided by Knowledge $\mathrm{E}$

Muhammad Subekti. This article is distributed under the terms of the Creative Commons Attribution License, which permits unrestricted use and redistribution provided that the original author and source are credited.

Selection and Peer-review under the responsibility of the ICONETS Conference Committee.

\section{S OPEN ACCESS}

Keywords: flow model, turbulence, temperature distribution, pebble-bed, HTR

\section{Introduction}

The safety analysis of High Temperature Reactor (HTR) based on pebble-bed fuel relies on nuclear physics calculation as well as experiment for validation. The analysis includes neutronics and thermal-hydraulics to predict the neutron flux and thermal generation values. The cooling fuel is one of the three safety concepts besides controlling reactor containing radiation. Furthermore, the temperature distribution in spherical pebble-bed fuel is determined by several parameter inputs such as coolant flow model, pressure, and temperature inlet and flow rate. In case of thermal-hydraulics one dimension (1D) calculation for characterizing the temperature distribution, the analytical codes such as THERMIX or VSOP have been utilized [1-2]. However, the three dimension (3D) calculation based on Computational Fluid Dynamics (CFD) has been carried out to study more detail the interior effect for 3D flow [3-5]. This detail analysis determines more accurate energy balance by detail model development. Therefore, the safety analysis using CFD code could inform the transient accident condition due to air ingress [4] as well as water ingress with detail temperature distribution in reactor core. The utilization of RSM has been investigated for relation of Nu number on different pebble layers under variable particle Reynold number [5], loss of coolant accident [6], and modeling height of $0.2 \mathrm{~m}$ [7]. Hence, RSM could be used as analysis comparator standard in this research. 
In normal operation, steady state CFD calculation requires more detail boundary condition, consisted of three pebble arrangements of Simple Cubic (SC), Body-Centered Cubic (BCC) and Face-Centered Cubic (FCC). A realistic pebble arrangement for a pebble-bed reactor core is combination of different structured arrangements and it is crucial to investigate the effects of pebble arrangement on the thermal-hydraulics characteristic for safety operation [7]. Therefore the investigation of turbulence models based on different pebble arrangements is required as well to be investigated. Beside laminar model, a CFD calculation could utilize other turbulence model such as $k-\epsilon, k-\omega$, and Reynold stress Model (RSM). The comparison between turbulence models is relevant due to low flow rate of HTR-10 about $4.3 \mathrm{~kg} / \mathrm{s}$. The Eddy Viscosity Model (EVM) [8] and RSM has been utilized in CFD calculation with insignificant result different [9]. Hence, the further investigation is important using the turbulence model of laminar, Spalart-Allmaras, $k-\epsilon, k-\omega$, and RSM.

The research aims is to analyze the effect of turbulence models on temperature and coolant velocity distribution on pebble-bed typed HTR. The simplest validation was done as well using analytical analysis. For next step, the CFD calculation was carried out with FCC fuel arrangement and utilized the turbulence models of laminar, Spalart-Allmaras, $k-\epsilon, k-\omega$, and RSM. Finnaly, the analysis compared the calculation results and find a best turbulence model for HTR-10 CFD calculation.

\section{Theory}

HTR-10 is a high temperature gas cooled reactor with reactor power of $10 \mathrm{MWt}$. Core consists of 27,000 spherical pebble-bed fuels with diameter of $6 \mathrm{~cm}$. Reactor core height and diameter are $197 \mathrm{~cm}$ and $180 \mathrm{~cm}$, respectively, with Helium coolant flow rate of $4.3 \mathrm{~kg} / \mathrm{s}$. More technical information of the general pebble-bed fuel characterisitics of HTR-10 is described in Table 1.

TABLE 1: General pebble-bed fuel characterisitics of HTR-10 [4].

\begin{tabular}{|l|l|}
\hline \multicolumn{1}{|c|}{ Parameter } & \multicolumn{1}{c}{ Value } \\
\hline Core power & $10 \mathrm{MWt}$ \\
\hline Core flowrate & $5.3 \mathrm{~kg} / \mathrm{s}$ \\
\hline Core's heigh / diameter & $197 \mathrm{~cm} / 180 \mathrm{~cm}$ \\
\hline Fuel element (FE) number & 27,000 \\
\hline Sphere diameter of pebble-bed fuel & $6.0 \mathrm{~cm}$ \\
\hline Wall material & Graphite \\
\hline Coolant & Helium \\
\hline Fluid pressure & $3 \mathrm{MPa}$ \\
\hline Inlet / outlet Temperature & $250^{\circ} \mathrm{C} / 700^{\circ} \mathrm{C}$ \\
\hline Average thermal power & $0.36 \mathrm{~kW} / \mathrm{FE}$ \\
\hline
\end{tabular}

The heat transfers from pebble fuel to Helium coolant by force convection. The turbulence flow considers the Laminar, Spalart-Allmaras, $k-\epsilon, k-\omega$, and RSM. However, the analytical calculation still could be used for benchmarking the temperature different $(\Delta T)$ during core heating $(Q)$ with certain flow rate $(\dot{m})$ in which $C_{p}$ is specific heat. The classical equation for analytical calculation is described below [2]:

$$
Q=\dot{m} C_{p} \ddot{A} T
$$




\section{Laminar Model}

Laminar flow through spherical-pebble bed fuel could be driven by Reynold number. The laminar model has been utilized on pebble-bed calculation [10]. In case of porous media, the calculation has utilized laminar model as well [11]. However, due to the condition of narrow gap in area contact of spherical-fuel, however the turbulence model is relevant to be utilized in CFD calculation as well.

\section{Spalart-Allmaras Model}

Spalart-Allmaras model is simple one-equation model that is originally from a low-Reynold number model for solving the turbulent viscosity. The transport equation for turbulence kinematic viscosity $\tilde{v}$ is described below [12]:

$$
\frac{\partial}{\partial t}(\rho \tilde{v})++\frac{\partial}{\partial x_{i}}\left(\rho \tilde{v} u_{i}\right)=G_{v}+\frac{1}{\sigma_{\tilde{v}}}\left[\frac{\partial}{\partial x_{i}}\left\{(\mu+\sigma \tilde{v}) \frac{\partial \tilde{v}}{\partial x_{i}}\right\}+C_{b 2} \rho\left(\frac{\partial \tilde{v}}{\partial x_{i}}\right)^{2}\right]-Y_{v}+S_{\tilde{v}}
$$

where $G_{v}$ is the production of turbulence viscosity and $Y_{v}$ is the destruction of turbulence viscosity that occurs in the near-wall region due to the wall blocking and viscous damping. Furthermore, $\sigma_{\tilde{v}}$ and $C_{b 2}$ are constants, while $S_{\tilde{v}}$ is a user-defined source term.

\section{k-epsilon Model}

The $k-\epsilon$ (k-epsilon) model is two-equation models in which the solution of two separate transport equations allows the turbulent velocity and length scales to be independently determined. The turbulence kinetic energy $k$, and its rate of dissipation, $\epsilon$, are obtained from the following transport equations $[6,12]$ :

$$
\frac{\partial}{\partial t}(\rho k)+\frac{\partial}{\partial x_{i}}\left(\rho k u_{i}\right)=\frac{\partial}{\partial x_{j}}\left[\left(\mu+\frac{\mu_{t}}{\sigma_{k}}\right) \frac{\partial k}{\partial x_{j}}\right]+G_{k}+G_{b}-\rho \epsilon-Y_{M}+S_{k}
$$

and

$$
\frac{\partial}{\partial t}(\rho \epsilon)+\frac{\partial}{\partial x_{j}}\left[\left(\mu+\frac{\mu_{t}}{\sigma_{\epsilon}}\right) \frac{\partial \epsilon}{\partial x_{j}}\right]+C_{1 \epsilon} \frac{\epsilon}{k}\left(G_{k}+C_{3 \epsilon} G_{b}\right)-C_{2 \epsilon} \rho \frac{\epsilon^{2}}{k}+S_{\epsilon}
$$

where $G_{k}$ is the he generation of turbulence kinetic energy due to the mean velocity gradients, $G_{b}$ is the generation of turbulence kinetic energy due to buoyancy, and $Y_{M}$ is the contribution of the fluctuating dilatation in compressible turbulence to the overall dissipation rate. $C_{1 \epsilon}, C_{2 \epsilon}$, and $C_{3 \epsilon}$ are constants. $\sigma_{k}$ and $\sigma_{\epsilon}$ are the turbulent Prandtl numbers for $k$ and $\epsilon$, respectively. $S_{k}$ and $S_{\epsilon}$ are user-defined source terms.

\section{k-omega Model}

The $k-\omega$ model is modifications based on the Wilcox $k-\omega$ model for low-Reynolds-number effects, compressibility, and shear flow spreading. The turbulence kinetic energy $k$ and the specific dissipation rate $\omega$ (omega) are obtained from the following transport equation [13]: 
and

$$
\frac{\partial}{\partial t}(\rho k)+\frac{\partial}{\partial x_{i}}\left(\rho k u_{i}\right)=\frac{\partial}{\partial x_{j}}\left(\Gamma_{k} \frac{\partial k}{\partial x_{j}}\right)+G_{k}-Y_{k}+S_{k}
$$

$$
\frac{\partial}{\partial t}(\rho \omega)+\frac{\partial}{\partial x_{i}}\left(\rho \omega u_{i}\right)=\frac{\partial}{\partial x_{j}}\left(\Gamma_{k} \frac{\partial \omega}{\partial x_{j}}\right)+G_{\omega}-Y_{\omega}+S_{\omega}
$$

where $G_{k}$ is the he generation of turbulence kinetic energy due to the mean velocity gradients, is the generation of $\omega$, and $\Gamma_{k}$ and $\Gamma_{\omega}$ are the effective diffusivity of $k$ and $\omega$, respectively. $Y_{k}$ and $Y_{\omega}$ are the dissipation of $k$ and $\omega$ due to turbulence. $S_{k}$ and $S_{\omega}$ are userdefined source terms.

\section{Reynold Stress Model}

Reynold Stress Model or RSM is a turbulence model that abandoning the isotropic eddyviscosity hypothesis. The RSM closes the Reynolds-averaged Navier-Stokes equations by solving transport equations for the Reynolds stresses, together with an equation for the dissipation rate. The equation of RMS is similar to the research has investigated the effect of FCC[7].

\section{Methodology}

To investigate the effect of turbulence model on coolant temperature and velocity, the research conducts (i) coolant modeling of HTR-10 core, (ii) validation using analytical analysis, and (iii) CFD calculation. The CFD calculation is based on FCC fuel arrangement and utilizes the five turbulence model of laminar, Spalart-Allmaras, , , and RSM. Furthermore, the analysis compares the calculation results based on five models and find best turbulence model for HTR10 CFD calculation.

TABLE 2: The property of coolant and wall at temperature of $500{ }^{\circ} \mathrm{C}$.

\begin{tabular}{|c|c|c|c|}
\hline & $\begin{array}{c}\text { Density } \\
{\left[\mathrm{kg} / \mathrm{m}^{3}\right]}\end{array}$ & $\begin{array}{c}\text { Specific heat } \\
{[\mathrm{J} / \mathrm{kg} \cdot \mathrm{K}]}\end{array}$ & $\begin{array}{c}\text { Thermal Conductivity } \\
{[\mathrm{W} / \mathrm{m} . \mathrm{K}]}\end{array}$ \\
\hline Helium & 1.86 & 5195 & 30.28 \\
\hline Carbon & 1790 & 710 & 86.70 \\
\hline
\end{tabular}

The coolant modeling for pebble-bed core HTR-10 based on FCC arrangement could be describe at Fig. 1 and the property of coolant and wall at temperature of $500^{\circ} \mathrm{C}$ in Table 2 are calculated by using KTA standard [14]. The model size is $33.00 \times 8.68 \times 8.68 \mathrm{~cm}$ with FCC arrangement. The total coolant flow rate of $4.3 \mathrm{~kg} / \mathrm{s}$ for core diameter of $180 \mathrm{~cm}$ is basis for the calculation that assumed flow rate through a coolant flow area of the model. In the physical model, total pebble fuel number is 28 Fuel Element (FE). The boundary wall of the coolant model limited the fuel number to $10 \mathrm{FE}$. Therefore, the total power in coolant model contained of 10 pebble fuel is $36 \mathrm{~kW}$ and assumed inlet temperature is $500^{\circ} \mathrm{C}$. The utilization of RSM is used as analysis comparator standard in this research. Each turbulence models are compared to RSM and analyzed the temperature and velocity distribution in the coolant. 


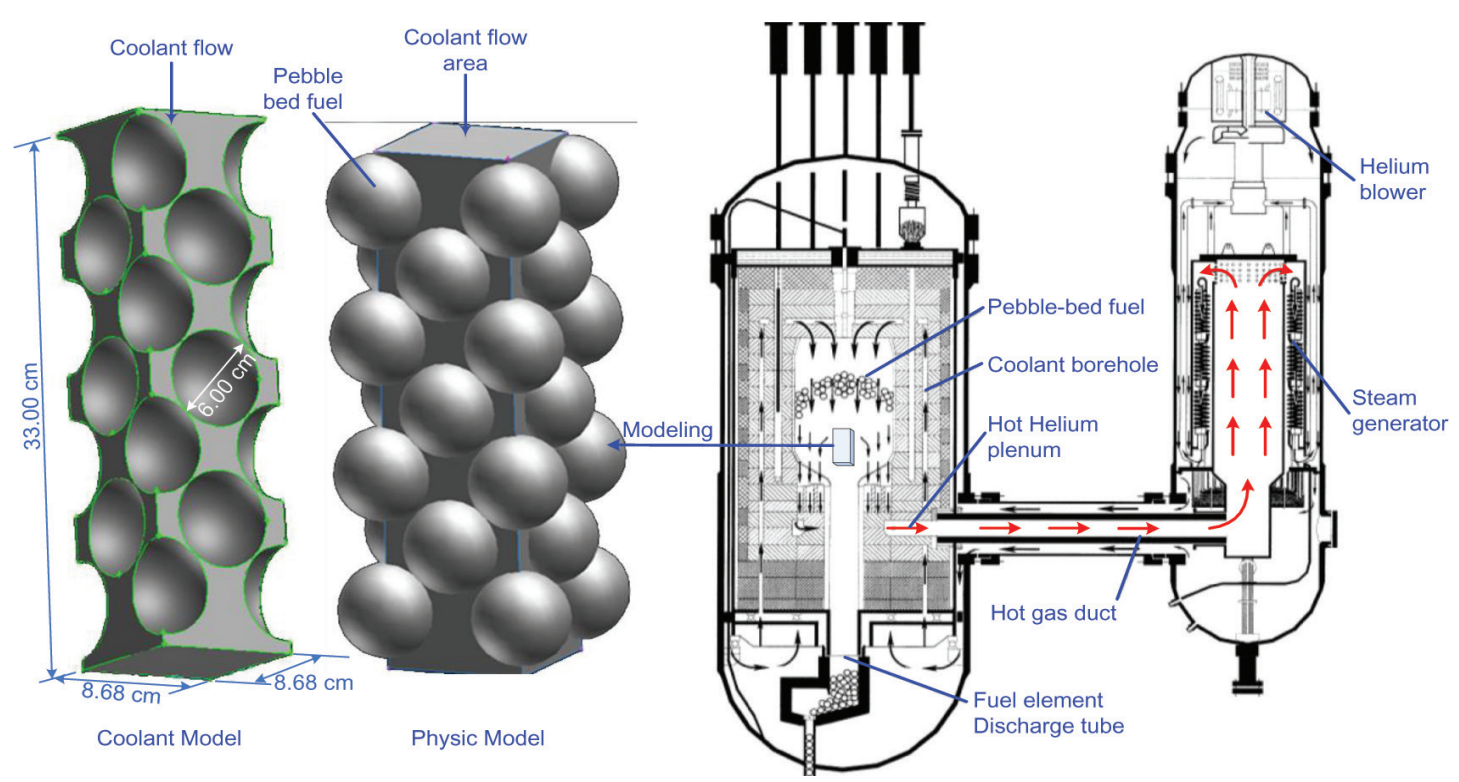

Figure 1: Coolant modeling for pebble-bed core HTR-10 based on FCC arrangement.

\section{Results and Discussions}

The comparison of temperature distribution to the variance of turbulence model in the Fig. 2 shows that all turbulence models have similar pattern of temperature distribution in which the coolant flows to bottom. However, the laminar model results insignificantly highest temperature distribution in bottom later due to low coolant flow-rate and short physical model height of $33 \mathrm{~cm}$. Furthermore, the low coolant flow-rate impacts on low Reynolds number in HTR-10's core.

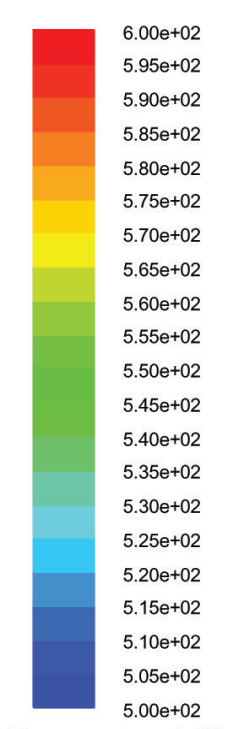

Temperature $\left[{ }^{\circ} \mathrm{C}\right]$

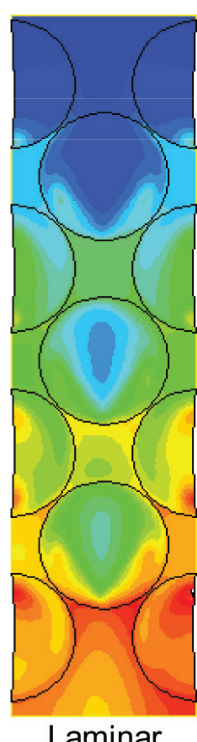

Laminar

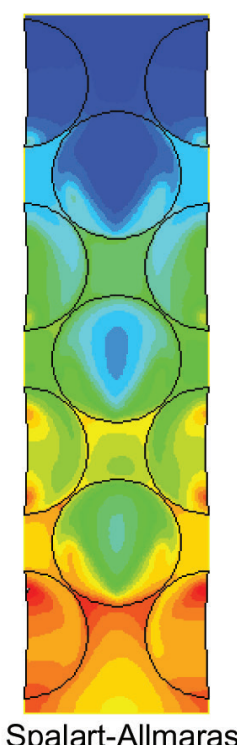

Spalart-Allmaras

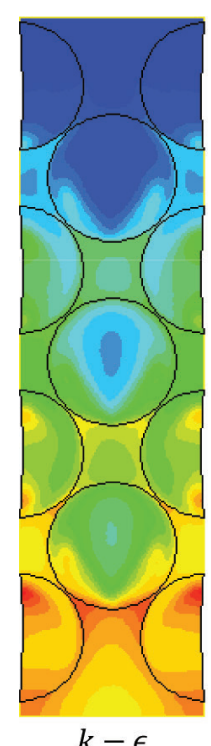

$k-\epsilon$

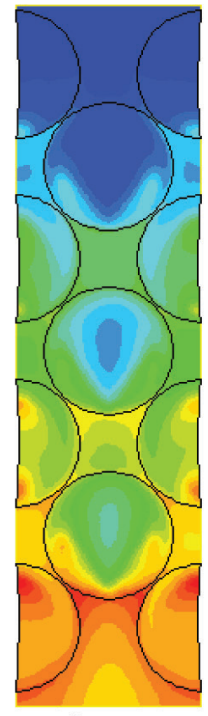

$k-\omega$

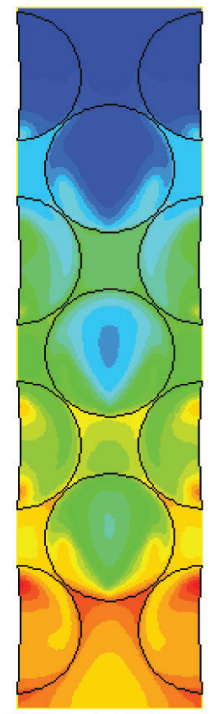

Reynold Stress

Figure 2a: Comparison of temperature distribution with variance of turbulence model.

The comparison of coolant velocity at certain position of $0.04 \mathrm{~cm}$ from bottom is shown in Fig. 2. The total physical model height as shown at Fig. 1 is $33 \mathrm{~cm}$ with inlet coolant area is $8.68 \times 8.68 \mathrm{~cm}$. The comparison points at certain position of $0.04 \mathrm{~cm}$ from bottom have 
a narrowing gap between four spherical pebble-beds so that the effect of turbulent will be strong in this area. However the contour of each coolant velocity shows almost similar pattern with the velocity within $1.63-6.50 \mathrm{~m} / \mathrm{s}$.

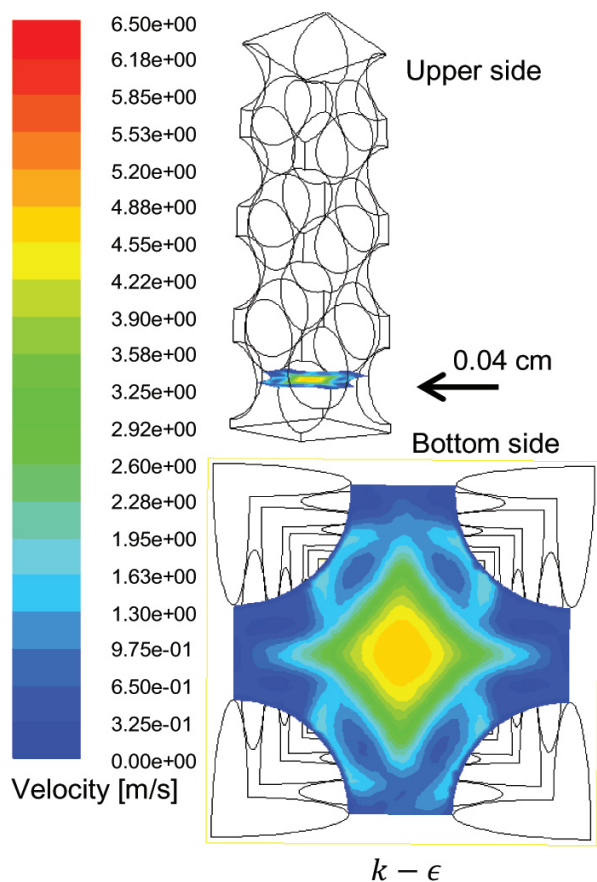

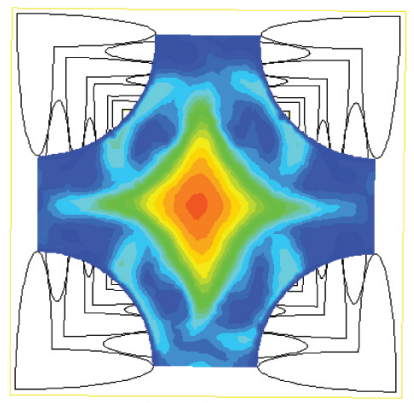

Laminar

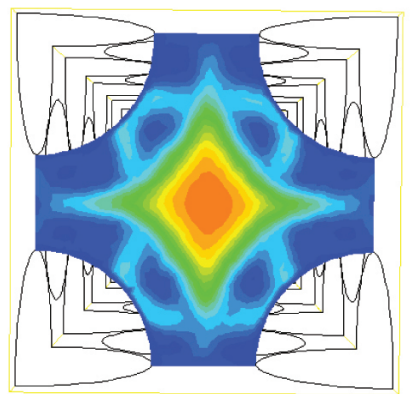

$k-\omega$

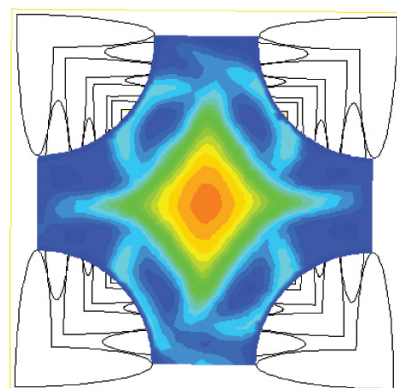

Spalart-Allmaras

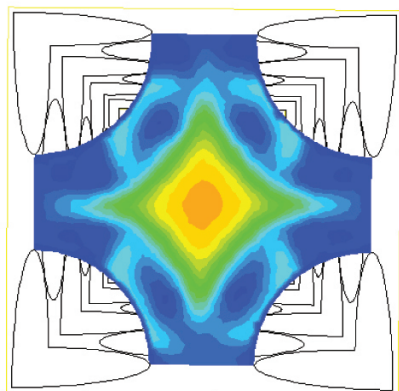

RSM

Figure 2b: The comparison of coolant velocity based on turbulence models at certain position of $0.04 \mathrm{~cm}$ from bottom.

Moreover, the validity of turbulence models could not be figured out before the experimental data availability. Therefore, the assessment of different choices of turbulence models could be based on analytical calculation by comparing temperature generated by CFD to the temperature generated from analytical calculation. Based on the equation (1), the temperature output of the modeling is $554.34 \mathrm{C}$. All turbulence models have average temperature results that are very close to the analytical calculation as shown in Table 3. The error varies from 0.03 to $0.33 \%$. Therefore, all turbulence models are relevant to be utilized in CFD calculation for HTR-10.

TABLE 3: Comparison of temperature based on turbulence models.

\begin{tabular}{|l|c|c|c|}
\multicolumn{1}{c|}{$\begin{array}{c}\text { Turbulence } \\
\text { Models }\end{array}$} & $\begin{array}{c}\text { Analytical } \\
\text { Output }\left[{ }^{\circ} \mathrm{C}\right]\end{array}$ & $\begin{array}{c}\text { Average } \\
\text { Output }\left[{ }^{\circ} \mathrm{C}\right]\end{array}$ & $\begin{array}{c}\text { Maximum } \\
\text { Output }\left[{ }^{\circ} \mathrm{C}\right]\end{array}$ \\
\hline Laminar & & $553.86(0.09 \%)$ & 583.09 \\
\hline Spalart-Allmaras & & $553.64(0.13 \%)$ & 580.12 \\
\hline k-epsilon & 554.34 & $552.49(0.33 \%)$ & 576.66 \\
\hline k-omega & & $554.15(0.03 \%)$ & 580.12 \\
\hline RSM & & $553.09(0.23 \%)$ & 579.13 \\
\hline
\end{tabular}

For more detail comparison, Fig. 3 shows the effect of turbulence model on coolant temperature and Fig. 4 for coolant velocity at certain position of $y=0.0400 \mathrm{~m}$ from bottom. The results in Fig. 3 and Fig. 4 agree to Fig. 2 that the different of turbulence models affect insignificant calculation results for temperature and velocity parameter. The calculated lines of coolant temperature and velocity for simpler laminar, Spalart-Allmaras, $k-\epsilon$, and $k-\omega$ 
model are close to RSM. Moreover, the closest line to RSM is $k-\epsilon$ model. The velocity peak at the coolant center in Fig. 4 shows that $k-\omega$ model is below RSM and very close to RSM. This phenomenon explains that the characteristic of $k-\omega$ model for expressing the turbulence separation line and swirl are identic to RSM.

The turbulence calculation using $k-\epsilon$ model assumes the similar ratio between Reynolds stress and mean rate of deformation $(\epsilon)$. Consequently, the $k-\epsilon$ model calculates dissipation $\epsilon$ is similar to RSM dissipation. Hence, the different of calculation result comes from other transport factors such as turbulence kinetic energy $k$ for $k-\epsilon$ model, production, diffussion, pressure strain interaction, and rotation transport for RSM. Comparing to RSM, $k-\epsilon$ model has faster computation time due to simpler equation. The utilization of algebraic equation for calculating Reynold stress $R_{i j}$ in RSM are not very stable and increase the computer time significantly. Therefore, the utilization of a simpler $k-\omega$ model is suggested beside an ideal RSM involving complex equation.

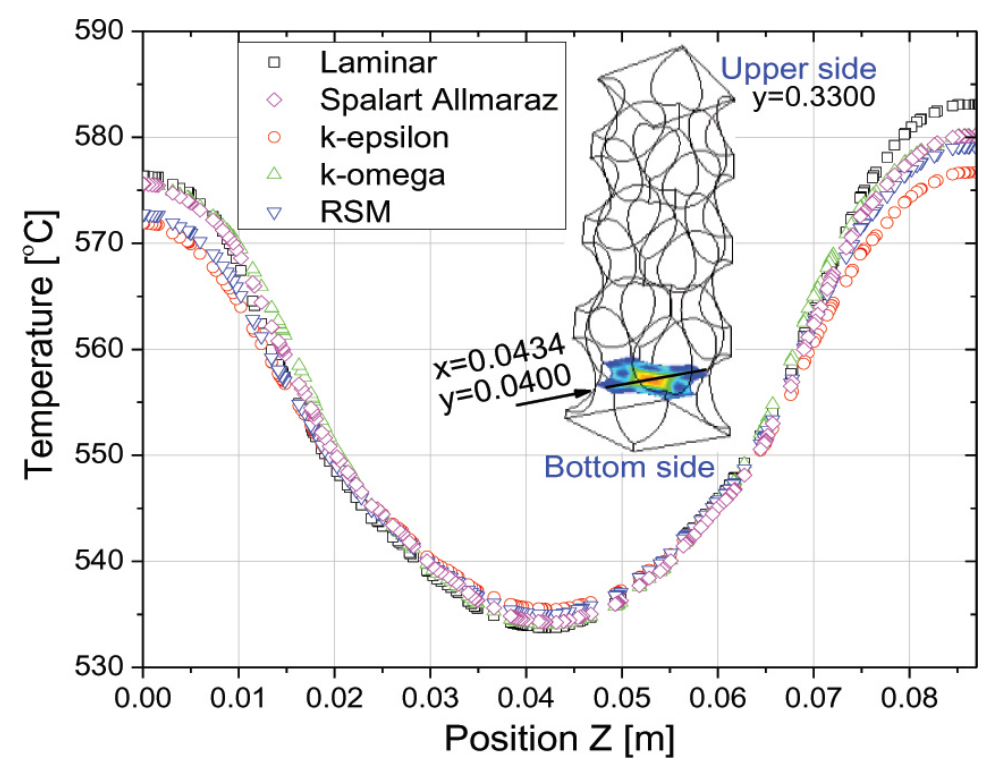

Figure 3: The effect of turbulence models on coolant temperature at certain position of $0.04 \mathrm{~m}$ from bottom.

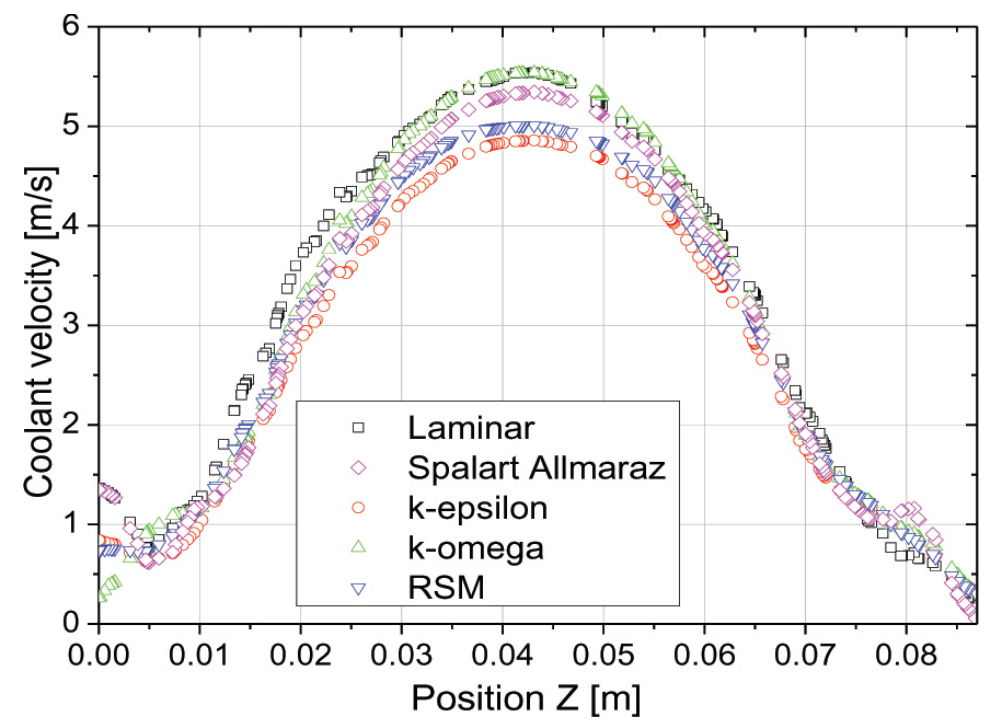

Figure 4: The effect of turbulence models on coolant velocity at certain position of $0.04 \mathrm{~m}$ from bottom. 


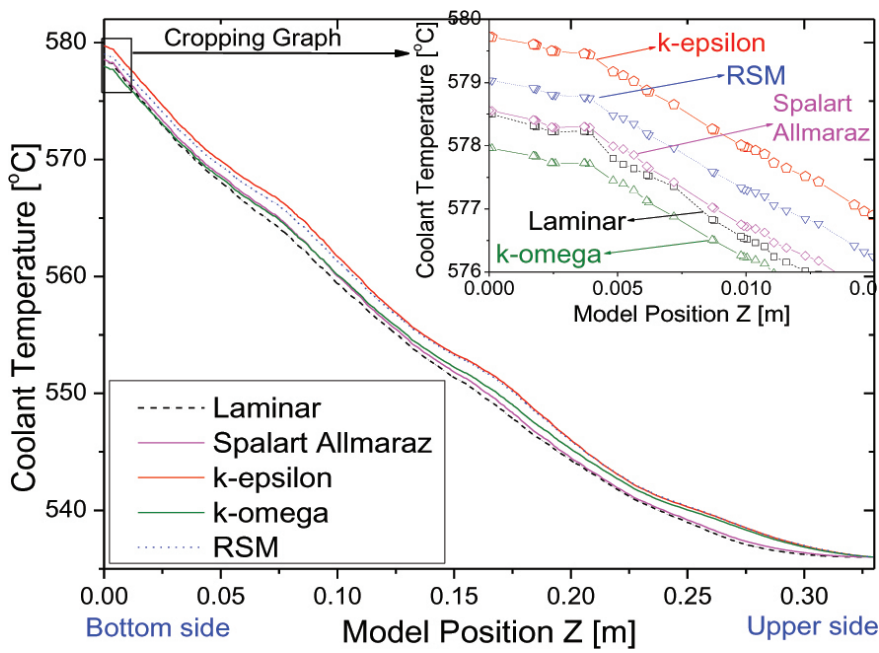

Figure 5: Effect of turbulence models on axial coolant temperature.

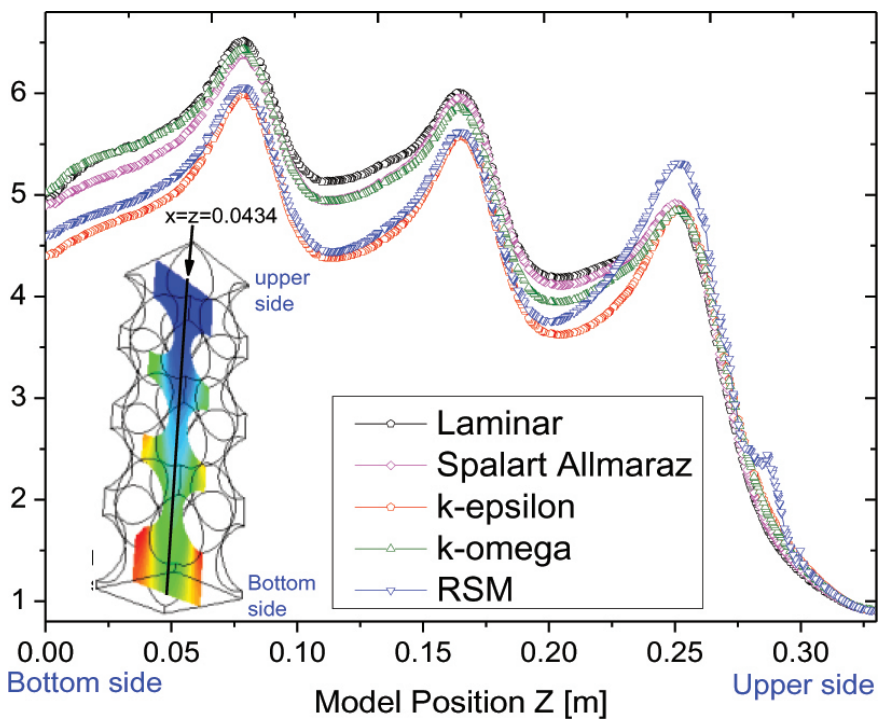

Figure 6: Effect of turbulence models on axial coolant velocity.

Furthermore, the calculation for axial temperature and velocity are analyzed as well. Fig. 5 describes the effect of turbulence model on axial coolant temperature at bottom side with position $\mathrm{x}=\mathrm{z}=0.0434$ and Fig. 6 for the axial coolant velocity. Peaks in Fig. 6 are due to the effect of flow-area narrowing of FCC pebble arrangement will increase the coolant velocity. In both Fig. 5 and Fig. 6, the line of each model has good agreement with Fig. 3 and Fig. 4, that all models have insignificant effect on coolant temperature and velocity, so all models are relevant to be utilized in CFD calculation for HTR-10 case. Good agreement is shown by the adjacent lines of $k-\epsilon$ and RSM. Considering the numerical stability risk and computation time of RSM, the utilization of $k-\epsilon$ model is suggested. The other models of Laminar, Spalart Allmaraz, and $k-\omega$ are acceptable to be adopt with more far space from ideal RSM. However, the characteristics of turbulence model may be different for other case based on different Reynolds number induced by fluid velocity. The different Reynolds number will affect to more significant transport factor from production, diffussion, pressure strain interaction, and rotation so that the separation line in turbulence flow could be more accurate for RSM. 
The comparison shows that the effects of turbulence models are insignificant on coolant temperature and velocity for HTR-10 case. The unavailability of experimental data tends the comparison to analytical calculation with different variation of $0.03-0.33 \%$ for temperature parameters. More detail comparison shows that the $k-\epsilon$ calculation result on temperature and coolant flow distribution are closest to RSM calculation results. The detail comparison shows that the axial and horizontal calculation results have similar agreement, so all model are acceptable to be adopt in CFD calculation. However, the characteristics of turbulence model may be different for other cases based on different Reynolds number induced by different fluid velocity. Considering the numerical stability risk, computation time cost, and closest computation result to RSM, the utilization of $k-\epsilon$ model is suggested for HTR-10 case.

\section{References}

[1] Xingqing, J. et al., "Prediction Calculation and Experiments for The First Criticality oh the 10 MW High Temperature Gas-Cooled Reactor-Test Module", Nuclear Engineering and Design, Vol.218, pp.43-49 (2002).

[2] IAEA-TECDOC-1382, "Evaluation of High Temperature Gas Cooled Reactor Performance: Benchmark Analysis Related to Initial Testing of The HTTR and HTR-10", IAEA, November, Vienna (2003)

[3] Du Toit, C.G. et al., "A System CFD Model of a Packed Bed High Temperature Gas-Cooled Nuclear Reactor", International Journal of Thermal Science, Vol.45, pp.70-85 (2006).

[4] Ferng, Y.M. and Chen, C.T., "CFD Investigating Thermal-Hydraulics Characteristic and Hydrogen Generation from Graphite-Water Reaction After SG Tube Rupture in HTR-10 Reactor", Journal of Applied Thermal Engineering, Vol.31, pp.2430-2438 (2011).

[5] Ferng, Y.M. and Lin, K.Y., "CFD Investigation of Thermal-Hydraulic Characteristics in a PBR Core Using Different Contact Treatments Between Pebbles", Annals of Nuclear Energy, Vol. 72, pp. 156-165 (2014).

[6] Ferng, Y.M. and Chi, C.W., "CFD Investigating the Air Ingress Accident in A HTGR Simulation of Thermal-Hydraulic Characteristics", Nuclear Engineering and Design, Vol.245, pp.28-38 (2012).

[7] Ferng, Y.M. and Lin, K.Y., "Investigating Effects of BCC and FCC Arrangements on Flow and Heat Transfer Characteristics in Pebbles Through CFD Methodology", Nuclear Engineering and Design, Vol.258, pp.66-75 (2013).

[8] Dixon, A.G., et al., "Systematic Mesh Development for 3D CFD Simulation of Fixed Beds: Single Sphere Study", Journal of Computer and Chemical Engineering, Vol.35, Issue 7, pp.1171-1185 (2011).

[9] Dehbi, A. and Martin, S.,"CFD Simulation of Particle Deposition on An Array of Spheres Using an Euler/Lagrange Approach", Nuclear Engineering and Design, Vol.241, pp.31213129 (2011).

[10] Yaser, H. and Khosrow, J., "Modeling of Laminar Forced Convection in Spherical-Pebble Packed Beds", Journal of Mechanical Science and Tech., Vol.26 (2), pp.643-649 (2012).

[11] Pedras, M.H.J. and de Lemos, M.J.S., "Macroscopic Turbulence Modeling for Incompressible Flow through Under-formable Porous Media", Journal of Heat Mass Transfer, Vol.44, pp.1081-1093 (2001). 
[12] Najar, N.A., et al.,"Comparative Analysis of $k-\epsilon$ and Spalart-Allmaras Turbulence Models for Compressible Flow through a Convergent-Divergent Nozzle", The International Journal of Engineering and Science (IJES), Vol.2, Issue 8, pp.8-17 (2013)

[13] Wilcox, D.C., "Formulation of The $k-\omega$ Turbulence Model Revisited", AIAA Journal, Vol. 46, No.11, pp.2823-2838 (2008).

[14] "Reactor Core Design of High-Temperature Gas-Cooled Reactors. Part 2: Heat Transfer in Spherical Fuel Elements", KTA 3102.2, Nuclear Safety Standards Commission (KTA), Duetsch (1983). 